\title{
Attitude commitment: Its impact on the similarity-attraction relationship*
}

\author{
RUSSELL VEITCH and WILLIAM GRIFFITT \\ Kansas State University, Manhattan, Kans. 66502
}

The degree to which target persons were "committed" to attitudes which were in agreement or disagreement with those of Ss was investigated with respect to influence on attraction. Commitment and proportion of similar attitudes were found to interact in the determination of attraction. Additionally, main effects for commitment and for proportion of similarity were found on two separate measures designed to ascertain any differences across experimental conditions in Ss' evaluation of the target as an agent of consensual validation.

The positive relationship between attitudinal similarity and attraction is one of the most reliable phenomena in the literature of social psychology. The generality of the relationship has been demonstrated across cultures, age groups, and occupational groups and in and out of the laboratory setting (Griffitt, in press). Within a reinforcement framework (Byrne \& Clore, 1970), similar and dissimilar attitudes are hypothesized to act, respectively, as positive and negative reinforcers which elicit positive and negative affective responses in Ss. Any stimulus, including a person, associated with such reinforcers becomes a conditioned stimulus capable of evoking positive and negative affective responses which, in turn, mediate subsequent evaluative responses to these stimuli. That similar and dissimilar attitudes can, in fact, function as positive and negative reinforcements is amply documented (Byrne, 1971).

The reinforcement properties of attitudes are widely assumed to derive from a general motive to be logical, accurate, and correct in interpreting or responding to one's environment. With respect to the social environment, the accuracy, logic, and correctness of one's beliefs and attitudes concerning such issues as politics, war, religion, etc., may be evaluated only by social comparison (Festinger, 1954) with others. Consensual validation (agreement) and consensual invalidation (disagreement) thus serve, respectively, as satisfiers and frustrators of this motive, i.e., as positive and negative reinforcers. Through the conditioning procedure outlined above, persons who provide consensual validation (agreement) are positively evaluated and those who provide consensual invalidation (disagreement) are negatively evaluated (Byrne, 1971).

Griffitt (in press) has suggested that variables which influence the degree to which Ss perceive persons as

*This research was supported in part by Research Grant MH 16351-01 from the National Institute of Mental Health to the second author. adequate agents of consensual validation or invalidation should influence the effects of agreement-disagreement on Ss' attraction to such persons. That is, the similarity-attraction relationship should be weakest when persons are "inadequate" or nonpowerful validating or invalidating agents and strongest when persons are powerful agents of validation or invalidation. For example, persons whose attitudes are unstable, unsupported, held for defensive reasons, or very common in the population at large might function as weak validators or invalidators of one's own attitudes. On the other hand, other's attitudes that are very stable, well supported, nondefensive, and uncommon should be more powerful positive or negative reinforcers. Available findings (Griffitt, in press) generally support the hypothesis that attitude similarity and attraction are more strongly related under the latter than under the former set of conditions.

The present experiment was designed to test predictions that the degree to which a target person expressed "commitment" to his attitudes would interact with the extent to which such attitudes were in agreement or disagreement with those of $S$ in determining attraction to the target. It was proposed that attitudes to which a target was highly committed (agreeing or disagreeing) would serve as more powerful items of consensual validation or invalidation than would items to which the target was relatively uncommitted (agreeing or disagreeing). That is, the "impact" (Byrne, London, \& Griffitt, 1968) of agreement-disagreement on attraction responses was hypothesized to vary positively with the degree to which targets were committed to their attitudes.

\section{METHOD}

Forty Ss, recruited from the introductory psychology classes and previously pretested on a 24-item attitude questionnaire, appeared for the experimental session in mixed-sex groups of from three to four. Ss were read a standard set of attitude-judgment instructions indicating that their task was to form judgments about an anonymous student on the basis of inspection of the stranger's responses to the attitude questionnaire (Byrne, 1971). In addition, following each attitude item was a four-point rating scale on which the stranger's degree of commitment to each attitude item was indicated. The attitude and commitment responses were, in fact, prepared by $E$ to conform to one of four prescribed specifications. The questionnaire had been completed to agree with the $S$ on either 1.00 or .00 of the items (see Griffitt \& Byrne, 1970) and the alleged student was either "very committed" or "uncommitted" on all the items. "Very committed" was operationalized for the $S$ by the statement: "This is how I feel today; I will definitely feel this way tomorrow." "Uncommitted" was operationalized for the S as: "This is how I feel today; I could change my mind by tomorrow." Thus, a 2 (proportion of similarity) by 2 
Table 1

Mean Attraction Responses as a Function of Proportion of Similar Attitudes and Stranger Commitment

\begin{tabular}{ccc}
\hline & \multicolumn{2}{c}{ Commitment } \\
\cline { 2 - 3 } & 1.00 & \\
Proportion & Very & 1.00 \\
of Similarity & Committed & Uncommitted \\
\hline 1.00 & $12.30_{\mathrm{a}}$ & $9.10_{\mathrm{b}}$ \\
0.00 & $5.00_{\mathrm{c}}$ & $6.60_{\mathrm{c}}$ \\
\hline
\end{tabular}

Note-Means with a common subscript do not differ significantly at the .05 level by the Newman-Keuls test.

(commitment) analysis of variance design was created, with 10 Ss per cell.

After examining the completed questionnaire, Ss were asked to record their judgments of the stranger on the Interpersonal Judgment Scale (IJS). The scale consists of six seven-point scales on which Ss record their impressions of the stranger's intelligence, knowledge of current events, morality, adjustment, likeability, and desirability as a work partner. Ratings on the last two scales are summed to provide a measure of attraction which ranges from 2 (negative) to 14 (positive), with a split half reliability of .85 (Byrne \& Nelson, 1965). An additional two questions of the same format were added to the IJS. The first was designed to ascertain Ss' evaluation of the target person as someone from whom they would seek opinions, and the second was designed to have Ss evaluate the target with respect to how helpful he would be in testing opinions.

After returning the completed IJS and faked attitude questionnaires, Ss were given a thorough account of the purposes of the study and the deception involved, were asked not to discuss the experiment with other students, and were dismissed.

\section{RESULTS}

Analysis of variance of the summed measure of attraction revealed a significant effect due to proportion of similarity $(\mathrm{F}=55.63, \mathrm{df}=1 / 36, \mathrm{p}<.001)$. The means of the 1.00 and .00 proportion of similarity conditions were 10.70 and 5.80, respectively. Additionally, the predicted proportion of Similarity by Commitment interaction was obtained $(F=13.35$, $\mathrm{df}=1 / 36, \mathrm{p}<.001)$. Means are presented in Table 1 , along with the results of a Newman-Keuls individual means comparison.

Evaluative responses regarding the target's knowledge of current events were affected reliably by only the proportion of similarity manipulation $(\mathrm{F}=11.47$, $\mathrm{p}<.01$ ), with the proportionally more similar target seen as more knowledgeable. Analysis of the S's ratings of the target's adjustment revealed a main effect for the commitment variable $(F=7.98, p<.01)$, where the stranger who was committed to his attitudes across the similarity dimension was seen as better adjusted. The means of the ratings of the committed and uncommitted targets were 4.70 and 3.75 , respectively. Ratings of adjustment were also influenced significantly by the similarity manipulation $(\mathrm{F}=30.28, \mathrm{p}<.001)$. The mean rating of adjustment for the 1.00 similar target was 5.65 ; whereas the mean adjustment rating for the .00 similar target was 3.30. There was no interaction effect for these two variables.
The very committed targets across conditions of similarity were seen as more intelligent $(F=5.48$, $\mathrm{p}<.05$ ), yielding a mean rating of 4.70 as compared to 4.00 for the uncommitted target. Intelligence ratings were also affected by the similarity manipulation $(\mathrm{F}=11.18, \mathrm{p}<.01)$, with the attitudinally more similar target seen as more intelligent. Ss' evaluations of the target person's morality were not affected in any consistent way by the experimental manipulations.

Evaluative responses regarding the target as someone $\mathrm{S}$ would seek the opinions of were affected by commitment $(\mathrm{F}=14.51, \mathrm{p}<.001)$ and by proportion of similarity $(\mathrm{F}=21.41, \mathrm{p}<.001)$. Mean evaluative responses to committed and uncommitted targets were 3.60 and 2.20, respectively, and to similar and dissimilar targets 3.75 and 2.05 , respectively. The same pattern of results was obtained with respect to Ss' evaluations of the target as someone with whom they would be likely to test their own opinions of the world. A significant effect for commitment $(\mathrm{F}=12.91, \mathrm{p}<.01)$ was reflected in means of 4.10 for committed as opposed to 2.85 for uncommitted targets. Additionally, the proportionally more similar target was evaluated as a more likely candidate for testing one's own ideas than was the proportionally dissimilar target $(\mathrm{F}=25.31$, $\mathrm{p}<.001)$. The mean evaluations were 4.35 and 2.60 , respectively.

\section{DISCUSSION}

It was proposed that the degree to which a target person expressed commitment to his attitudes would interact with the extent to which such attitudes were in agreement or disagreement with those of $S$ in determining S's attraction to the target. Results indicated the predicted interaction effect as well as a main effect for proportion of similarity. It was further proposed that the explanatory concepts underlying such an interaction derive from the need of individuals to be accurate, logical, and correct in interpreting or responding to their environment, and the notion that attitudes about one's social environment may only be evaluated by social comparison (Festinger, 1954) with others. A main effect for commitment regarding the "opinion-seeking" and "opinion-testing" measures was therefore predicted, i.e., targets who were committed to their attitude statements would serve as more powerful agents of consensual validation and would, therefore, be seen as more likely candidates from which to seek opinions or as more helpful candidates in testing presently extant opinions. These relationships, as previously noted, were obtained.

The main effects for proportion of similarity on these three response measures were not surprising inasmuch as proportion of similarity has been shown to affect a wide variety of interpersonal evaluative responses (see Byrne, 1971). That the evaluative responses regarding the target's helpfulness in testing opinions and his ratings with respect to Ss seeking his opinions should be affected by the proportion of similarity manipulation is consistent with the reinforcement-affect model of Byrne \& Clore (1970). The interaction effect on the attraction measure, however, does bear out the prediction that commitment and noncommitment have, respectively, strengthening and dampening effects on the impact of attitudinal statements in determining attraction responses.

\section{REFERENCES}

Byrne, D. The attraction paradigm. New York: Academic Press, 1971 . 
Byrne, D.. \& Clore, G. L. A reinforcement model of evaluative responses. Personality: An International Journal, 1970, 2 103-128.

Byrne, D., London, O., \& Griffitt, W. The effect of topic importance and attitude similarity-dissimilarity on attraction in an intrastranger design. Psychonomic Science, 1968, 11 , 303-304.

Byrne, D. \& Nelson, D. Attraction as a linear function of proportion of positive reinforcements. Journal of Personality \& Social Psychology, 1965, 1, 659-663.

Festinger, L. A theory of social comparison processes. Human
Relations, 1954, 7, 117-140.

Griffitt, W. Attitude similarity and attraction. In T. L. Huston (Ed.), Perspectives on interpersonal attraction. New York: Academic Press, in press.

Griffitt, W., \& Byrne, D. Procedures in the paradigmatic study of attitude similarity and attraction. Representative Research in Social Psychology, 1970, 1, 33-48.

(Received for publication January 24, 1973.) 